\title{
The green bulkhead: a vertical wetland design for urban harbors
}

\begin{abstract}
In urban harbors there is a reliance on the "gray infrastructure" of armored bulkheads along shorelines. While this form of shoreline technology provides stability and eliminates erosion, it limits shoreline biodiversity and lacks aesthetic value. In this paper, a living shoreline concept, termed the Green Bulkhead, is described and demonstrated. This is a kind of artificial vertical wetland with plants grown in a porous plastic fabric that is draped over the surface of an existing bulkhead. The system is irrigated with water that is pumped from the harbor. Several alternate designs have been tested for different medium types, planting patterns and water pumping regimes. It is proposed that the green bulkhead system can provide limited treatment wetland services in an urban setting where cost-effective water quality management options are minimal. Testing found that high percentages of sediment were retained within the matrix of the different media. The system has aesthetic benefits by "greening" the harbor environment with wetland plants and, because of its vertical orientation, it can be managed adaptively for sea level rise. This work is a report of an on-going ecological engineering project with demonstrations along the Baltimore, Maryland Inner Harbor and the Anacostia Waterfront in Washington, DC.
\end{abstract}

Keywords: green bulkhead, vertical wetland, ecotechnology, sediment removal
Volume 8 Issue 3 - 202I

\section{Peter I May, Matthew Lagomarsino, Patrick Kangas}

Department of Environmental Science and Technology, University of Maryland, USA

Correspondence: Peter I May Department of Environmental Science and Technology, University of Maryland, College Park, Maryland 20742, USA, Tel 443-690-702I, Email pimay@umd.edu

Received: April 22, 2021 | Published: May 20, 2021

\section{Introduction}

As natural wetlands continue to be replaced by development or impacted by other human disturbance, various means are being employed to compensate for the losses. Restoration is done where possible but the creation of new kinds of wetlands is also used for mitigation. Special challenges for mitigation occur in highly urbanized areas with shorelines of tidal and non-tidal waters. Wetlands are removed by urban development because of the high value of the land area. ${ }^{1,2}$ In most cases urban shorelines are characterized by hardening with bulkheads which control erosion and provide stabilization, but which also impact adjacent aquatic communities. ${ }^{3,4}$ However, the artificial structures of bulkheads generate new habitats for organisms ${ }^{5,6}$ and creative designs are emerging to enhance the aquatic ecological systems along urban shorelines. ${ }^{7-10}$ In this paper a new type of vertical wetland, termed the Green Bulkhead, is described for deployment in urban harbors that are lined with hardened bulkheads.

The Green Bulkhead is a living shoreline concept in the form of a vertical wetland designed for deployment along armored bulkheads. The system consists of a porous, recycled plastic fabric that is draped over the surface of an existing bulkhead. Wetland plants are grown in artificial growth media that is placed in pockets of the plastic fabric. Water is pumped from the adjacent harbor to the top of the system where it flows by gravity through the planted fabric back down to the harbor. Figure 1 is an energy circuit diagram of the Green Bulkhead system with emphasis on removal of suspended sediments. Harbor water containing suspended sediments $(\mathrm{S})$ is shown being pumped through the system consisting of plants, growth media and the support structure of the plastic fabric. Percent removal of sediments is found by dividing the sediment concentration leaving the system on the righthand side of the diagram by the sediment concentration in the harbor water entering the system on the left-hand side of the diagram. The Green Bulkhead design has been developed over several years with extensive trials of different support materials, plant species, growth media and pumping mechanisms. It was inspired by natural vertical wetlands such as hanging gardens. ${ }^{11,12}$ or spray cliff communities ${ }^{13}$ where surface water flows over vegetation on rock surfaces. The Green Bulkhead has been tested in Baltimore Harbor with brackish plant species including Sporobolus alterniflorus, Sporobolus pumilus, Scirpus pungens, and Juncus roemerianus, and along the waterfront in Washington DC with freshwater plant species including Iris versicolor, Solidago sempervirens, Hibiscus moscheutos, Saururus cernuus and Lobelia cardinalis.

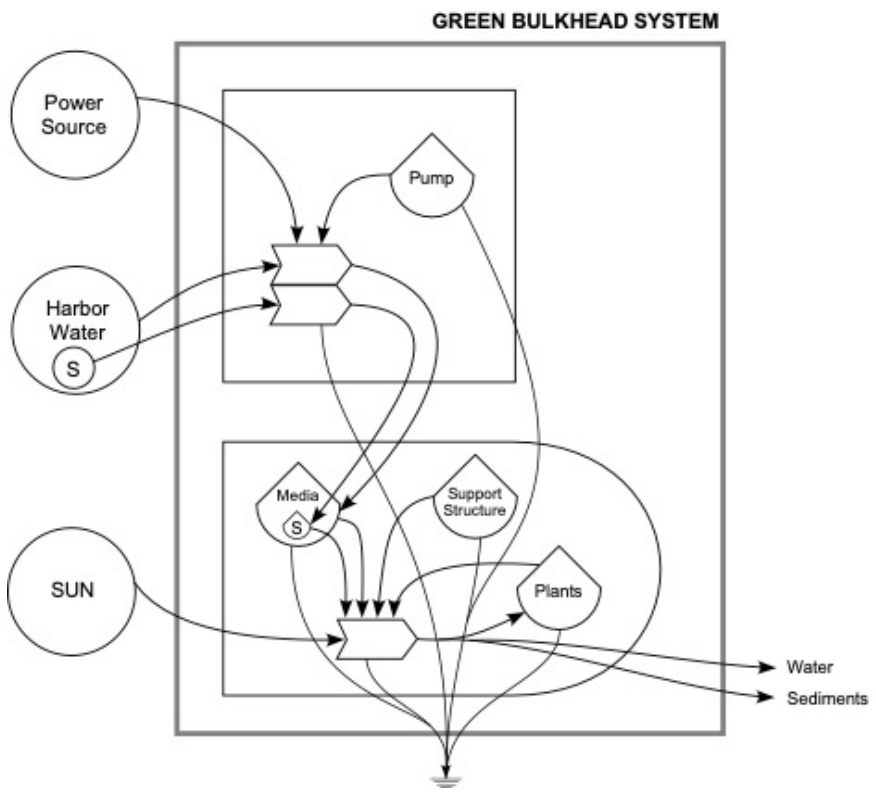

Figure I Energy circuit diagram of the Green Bulkhead system. The pumping component is shown above the plastic fabric that contains the growth media and the wetland plants.

S, sediment. 


\section{Materials and methods}

The experimental Green Bulkhead was constructed and tested to assess the potential for the system to remove suspended sediments as an index of functional performance. The experimental unit used in this study consisted of a $180 \mathrm{~cm}$ x $120 \mathrm{~cm}$, double-layer of Poly-Flow recycled plastic sheets (Americo, Acworth, GA) suspended on an aluminum frame with parallel rows of pockets made from horticulture fabric that were sown between the Poly-Flow sheets and which contained the media for growing plants. A wooden support frame and plastic lined basin was positioned at the base of the frame to hold water that is pumped over the system during experimentation. For continuous operation water could be pumped from the basin to the top of the Poly-Flow sheet thorough a plastic hose. A diffuser pipe was connected to the hose at the top of the frame that allowed the water to be discharged evenly along the top of the Poly-Flow sheet. The pumped water through the diffuser pipe flows downward by gravity through the Poly-Flow sheet containing the media-filled pockets to the basin at the base of the frame. Testing was done before the start of the experimental runs to insure an even flow of the pumped water through the system. Two types of plant growth media were tested in the Green Bulkhead: coconut husk "coir" matting ${ }^{14}$ and spun mineral rockwool. ${ }^{15}$

During the sediment removal experimental runs water was not recirculated but rather a single-pass, input-output approach was used for measuring suspended sediment removal by the Green Bulkhead system. No plants were used for experimental tests of the different media to avoid the confounding effects of different degrees of root structures and densities on sediment trapping. A batch of suspended sediments was prepared in a 19-1 (5 gal) bucket by mixing a known dry mass of sediments, collected from a local stream bank, with a known volume of water. To insure that the sediments remained in suspension, the suspension was mixed by hand continuously during each experimental test. The suspension was pumped by submersible pump (Supreme Hydroponics/Danner $500 \mathrm{gph}$ ) from the sediment pool bucket to the top of the Green Bulkhead $(210 \mathrm{~cm})$ at approximately 18 liters per minute and was allowed to flow by gravity down through the media. Water was collected at the top of the system as it left the diffuser pipe and at the bottom of the system after it had passed through five rows of pockets filled either with coconut coir, rockwool or Poly-Flow medium alone. Thus, there were two treatments and one control. Sediment concentration was measured in three replicate water samples collected from the top and the bottom of the Green Bulkhead for each experimental trial of the system. The sampled water was filtered through VWR Grade 474 filter papers. Filter papers were dried at 60 degrees Celsius for 24 hours then weighed to determine the mass of sediments in the water sample. Three trials were conducted for each media type along with control runs in which no medium was used. Between trial runs the medium was removed and the entire system was spray washed with tap water to remove any residual sediments in the Poly-Flow sheets or in the porous horticultural fabric pockets. Sediment removed during passage through the green bulkhead is expressed as the percentage removed. Means of percent sediment removal between media types and the control were compared with T-tests after the data were shown to be normally distributed with a Shapiro Wilk's Test and a density plot.

\section{Results and discussion}

Both coconut coir and rockwool removed significantly more suspended sediments in comparison with the control runs which contained no added media, but no difference in removal was found between the two types of media (Figure 2). The coconut coir medium removed $79 \%$ of the suspended sediments, while the rockwool medium removed $78 \%$ of the suspended sediments. In contrast, $37 \%$ of the sediments were removed in the control runs that were operated only with the Poly-Flow and without any additional media in the experimental Green Bulkhead.

\section{Sediment Removal vs. Growth Media}

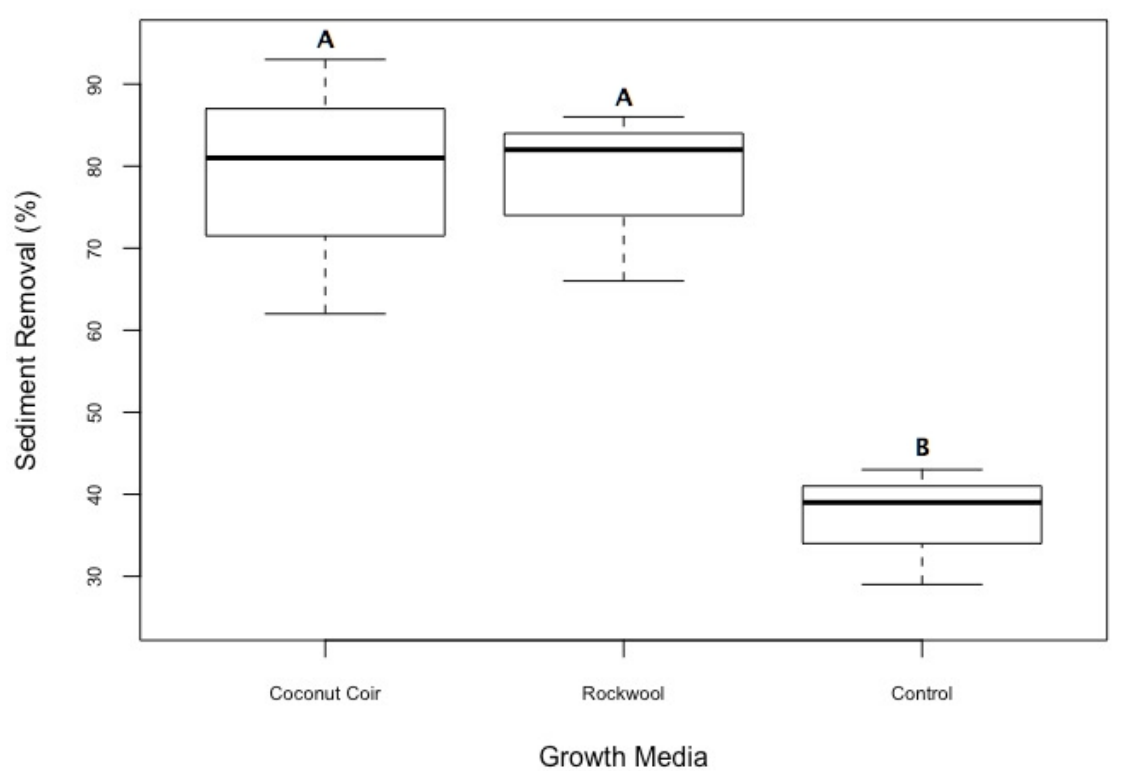

Figure 2 Comparison of the relative amount of suspended sediments removed by different media in the experimental Green Bulkhead.

Sediments are an important pollutant type that can reduce light transmission, physically impair aquatic organisms and transport other pollutants such as nutrients and toxins. In the Chesapeake Bay Watershed suspended sediments are one of the primary pollutants 
targeted for watershed-wide reductions along with the nutrients nitrogen and phosphorus. ${ }^{16}$ The sediment removal rates found in this study are on the same order of magnitude as for conventional treatment wetlands ${ }^{17}$ which demonstrates the ability of the Green Bulkhead to improve water quality. This finding is not surprising since the Green Bulkhead has similar kinds of physical/trapping processes as a natural wetland.

The testing of media types as done in this study is an important step in the design of ecologically engineered systems. ${ }^{18-20}$ In this study both media were found to remove suspended sediments at similar rates. While both medium types tested here are commercially available, differences in price favor coconut coir over rockwool. Coconut coir may also be more environmentally compatible in being organic and a reusable byproduct, since it is produced from discarded coconut husks.

Based on the results of this study it is proposed that the Green Bulkhead system can provide treatment wetland services in an urban setting where cost-effective water quality management options are limited. Under normal conditions the Green Bulkhead would be operated as a recirculating system with intermittent pumping from harbor waters so it has greater potential for water treatment than a single-pass treatment system such as a rain garden.

In addition to water quality improvement function, the Green Bulkhead has multiple potential benefits. Bulkheads are a common along urban shorelines and they provide no visual attraction to the setting. The Green Bulkhead has aesthetic appeal by "greening" a harbor environment with wetland plants. ${ }^{21}$ The reintroduction of wetland plants will provide habitat for beneficial insects, such as pollinators, and perhaps birds as well. The design of the Green Bulkhead is adjustable in that the plastic fabric holding the plants can be raised or lowered as appropriate or can be moved from one location to another. Finally, because of the vertical orientation of the system, the wetland plants in the Green Bulkhead are likely to be less exposed to herbivory by waterfowl herbivores such as resident Canada geese (Branta canadensis maximus), which is a common problem for restored or created wetlands in urban settings. ${ }^{22}$ Although the Green Bulkhead may offer multiple, potential benefits, drawbacks could include available electricity hook up and costs associated with pumping of water and maintenance of the infrastructure. Solar powered pumps would be a cost that would free the deployment of the system from an electrical grid hook up and after a solar photovoltaics purchase electricity would be free. Infrastructure maintenance would ideally be maintained by a local watershed group or waterfront management entity such as a port administration. The use of the Green Bulkhead in latitudes with seasonally cold climates where freezing will be an issue may require removal of the system. The modular design is intended to be easily handled so that prior to plant senescence and freezing it can be "winterized" by removing pumps and plants, with plants available to be used in any local wetland restoration projects and the physical structure stored for warmer weather re-deployment. Alternatively, the green bulkhead modules could be hung with plants in-situ in a greenhouse with periodic irrigation ready for re-deployment. Where winter freezing is not an issue the system can operate year-round. For all implementations it is expected that a partnership with a local watershed group or waterfront development corporation would be beneficial to be stewards of the system.

\section{Conclusion}

The Green Bulkhead is a new option for the design of rapidly redeveloping urban waterfronts that have long ago lost fringing wetlands. While not replicating most of the functions of natural wetlands, this novel approach has alternative value, especially where there is growing concern about sea-level increase eliminating the potential of wetland migration against hardened vertical bulkheads. ${ }^{24,25}$ The system has the potential to provide multiple benefits beyond modest and likely symbolic sediment load reduction for large urban riverine or tidal estuarine systems. These include aesthetic appeal and much like its horizontal analogue the floating wetland which uses similar materials, its use as a focal point for educational outreach about harbor restoration. In the future we hope to further investigate renewable power sources for pumping water and to look for opportunities for the implementation of large-scale examples of the Green Bulkhead ecotechnology.

\section{Acknowledgments}

A Hatch Grant from the USDA to the ENST Department of the University of Maryland provided partial support for this project. The authors acknowledge the work of Jose-Luis Izursa who drafted Figure 1. Special credit is due to the several undergraduate capstone classes of students at the University of Maryland who participated in the development of the Green Bulkhead. Excess Poly-Flow material from Floating Wetlands Solutions was provided by Biohabitats, Inc.

\section{Conflicts of interest}

The author declares that there is no conflict of interest.

\section{Funding}

None.

\section{References}

1. Schmid JA. Wetlands in the urban landscapes of the United States. The Ecological City. In: RM Platt, R A Rowntree, PC Muick, editors. University of Massachusetts Press, Amherst, MA; 1994. p. 106-133.

2. Faulkner S. Urbanization impacts on the structure and function of forested wetlands. Urban Ecosystems. 2004;7:89-106.

3. Gitman RK, Fodrie FJ, Popowich AM, et al. Engineering away our natural defenses: an analysis of shoreline hardening in the US. Frontiers in Ecology and the Environment.2015;13:301-307.

4. Gitman RK, Scyphers SB, Smith CS, et al. Ecological consequences of shoreline hardening: A meta-analysis. Bioscience. 2016a;66:763-773.

5. Dafforn KA, Glasby TM, Airoldi L, et al. Marine urbanization: an ecological framework for designing multifunctional artificial structures. Frontiers in Ecology and the Environment. 2015;13:82-90.

6. Glasby TM, Connell SD. Urban structures as marine habitats. Ambio. 1999;28:595-598.

7. Gitman RK, Peterson CH, Currin CA, et al. Living shorelines can enhance the nursery role of threatened estuarine habitats. Ecological Applications. 2016b;26:249-263.

8. Ash JS, Moschetto BJ, Musser R Jr, et al. Innovative mitigation for hardened seawall structures. In: Proceedings of the 27th Annual Conference on Ecosystem Restoration and Creation. Hillsborough Community College, Tampa, FL. 2000. p. 1-9.

9. DeWeerdt S. How to build a living seawall. Conservation Magazine. 2012;13(1):48-49.

10. Morris RL, Porter AG, Figueira WF, et al. Fish-smart seawalls: a decision tool for adaptive management of marine infrastructure. Frontiers in Ecology and Environment. 2018;16:278-287.

11. Malanson GP. The assembly of hanging gardens: effects of age, area, and location. American Naturalist. 1982;119:145-150. 
12. Malanson GP. Habitat and plant distribution in hanging gardens of the Narrows, Zion National Park, Utah. Great Basin Naturalist. 1980;40:178182.

13. Zartman CE, Pittillo JD. Spray cliff communities of the Chattooga Basin. Castanea. 1998;63:217-240.

14. Justiz-Smith Nilza G, Junior Virgo G, Buchanan Vernon E. Potential of Jamaican banana, coconut coir and bagasse fibres as composite materials. Materials Characterization. 2008;59:1273-1278.

15. Bougoul S, Boulard T. Water dynamics in two rockwool slab growing substrates of contrasting densities. Scientia Horticulturae. 2006;107(4):399-404.

16. Paolisso M, Trombley J, Hood RR, et al. Environmental Models and Public Stakeholders in the Chesapeake Bay Watershed. Estuaries and Coasts. 2015;38(Suppl 1):S97-S113.

17. Kadlec RH, Wallace S. Treatment Wetlands, 2nd Edition. CRC Press, Boca Raton, FL; 2009.

18. Prodanovic V, Hatt B, McCarthy D, et al. Green walls for greywater reuse: understanding the role of media on pollutant removal. Ecological Engineering. 2017;102:625-635.
19. Turker OC, Ture C, Yakar A, et al. Engineered wetland reactors with different media types to treat drinking water contaminated by boron (B). Journal of Cleaner Production. 2017;168:823-832.

20. Marin-Muniz JL, Garcia-Gonzalez MC, Ruelas-Monjardin LC, et al. Influence of different porous media and ornamental vegetation on wastewater pollutant removal in vertical subsurface flow wetland microcosms. Environmental Engineering Science. 2018;35:88-94.

21. Flies EJ, Skelly C, Negi SS, et al. Biodiverse green spaces: a prescription for global urban health. Frontiers in Ecology and Environment. 2017;15:510-516

22. May PI. Alternate State Theory and Tidal Freshwater Mudflat Experimental Ecology on Anacostia River, Washington, D.C. Dissertation. University of Maryland; 2007.

23. Dyson K, Yocom K. Ecological design for urban waterfronts. Urban Ecosystems. 2015;18:189-208.

24. Hill K. Coastal infrastructure: a typology for the next century of adaptation to sea-level rise. Frontiers in Ecology and Environment. 2015;13:468476. 